\title{
Successful-But Not Always Easy Going-Professional Career as a Female Vascular Surgeon and Mother of Four Sons
}

\author{
Dr. Simone Hofer, Vascular Surgeon, Switzerland
}

\author{
Markus Furrer ${ }^{1}$
}

Accepted: 25 July 2021/Published online: 4 August 2021

(C) Société Internationale de Chirurgie 2021

Simone Hofer was born in Zurich as the second child of a non-academic family. Being an excellent student, her mother always encouraged her to pursue a career just as much as she did encourage her older brother. As a child, she loved animals and volunteered in a veterinarian's office. At school she loved maths and natural sciences, yet, as the veterinary university was overloaded, she decided to go to medical school, following her brother's academic track. Her love of surgery did not present itself until her fifth year of medical school, but as soon as she experienced the operating room, she knew she had found home.

Surgery encompassed everything she admired: the technical skills, the direct approach, the emergent need for action, the ability of three dimensional thinking, the intellectual problem solving, preparing and planning the operation. By the time she had certified as a general surgeon, she had given birth to her third child and was working part-time. As she was not full time, the hospital where she worked did not allow her to work as a chief resident in general surgery, but rather asked her to choose a subspecialty. She decided to change to vascular surgery and joined the cardiovascular clinic of the University Hospital of Zürich. She started a vascular residency still part-time and completed the three years of training,

Markus Furrer

markus.furrer@ksgr.ch

1 Department of Surgery, Kantonsspital GR, Chur, Switzerland including the excellent training program in endovascular surgery. After her husband was appointed as the head of an urology unit the family moved to Chur, where Simone continued her vascular specialisation at the Kantonsspital. She completed the training program in 2010 with the European Board of Vascular Surgery Qualification (FEBVS). By this time, she had given birth to her fourth son, all the while continuing her professional career. Dr. Hofer became an experienced endovascular surgeon, one of few women in the field. Her research career has focused on improving patient's quality of care, resulting in important national and international presentations and manuscripts.

She became the Deputy Head of Vascular Surgery, responsible for the endovascular program, which she has grown over the years. She is a member of the National Board of the Swiss Vascular Surgical Society and one of the foremost national opinion leaders in endovascular surgery. She is a true role model, inspiring many of her residents, especially other women trainees, to pursue a career in surgery while having a family. She brings her passion for endovascular surgery, her thirst for understanding the scientific intricacies and optimization of patient outcomes to all interactions with trainees, which inspires them. Dr. Hofer demonstrates that it is possible to combine a splendid surgical career with a rich family life. She really does seem to "have it all". What has become clear is that for individuals to be successful in all aspects of life, it is not just through their own efforts, but also it is the duty of the healthcare and academic institutions to provide opportunities for well-rounded integration.

Dr. Hofer has a message to all trainees: "As in every competitive profession, you have to be ready to work hard (and sometimes more than the demanded working time). And keep in mind: Never give up!" 


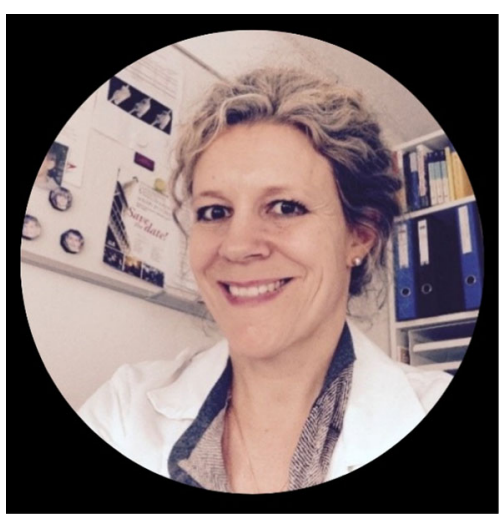

Publisher's Note Springer Nature remains neutral with regard to jurisdictional claims in published maps and institutional affiliations.

Dr. Simone Hofer, Vice-chair of vascular surgery at the Kantonsspital Chur, Switzerland, member of the Board of the Swiss Society of Vascular Surgery 